\title{
Sobre a seriedade do riso: \\ as relações do chiste com o inconsciente em Freud e a teoria do risível de Schopenhauer
}

\author{
About the seriousness of laughter: \\ the joke's relations with the unconscious in Freud \\ and Schopenhauer's Theory of Ludicrous
}

\author{
Eduardo Ribeiro da Fonseca \\ Doutor em Filosofia Moderna e Contemporânea pela USP, escritor e tradutor. \\ Professor de Filosofia da PUCPR. \\ E-mail: eduardorfonseca@uol.com.br
}

\begin{abstract}
Resumo: Um dos temas presentes na obra de Schopenhauer e que merecem uma análise a partir da psicanálise é a sua teoria do risível, que expõe análises peculiares acerca dos intelectos intuitivo e abstrato e, consequentemente, acerca das relações de linguagem. Dentro desta visão schopenhaueriana acerca do humor, como uma das suas expressões mais características, destaca-se o chiste, tema que entreteve por um breve momento o pensamento de Freud e lhe proporcionou um belo e elucidativo texto acerca das expressões cotidianas do inconsciente e que, dessa forma, elucida a expressão psíquica dos afetos em termos de deslocamento e condensação.
\end{abstract}

Palavras-chave: Pulsão; Intelecto; Humor.

Abstract: One of the subjects of Schopenhauer's works and that deserve an analysis based on psychoanalysis is your Theory of Ludicrous, that exposes peculiar analysis about the intuitive and abstract intellects and, consequently, about the human language. Within this Schopenhauer's point of view about the humour, as one of its most characteristic expressions, there is the joke, theme that has interested Freud for a brief moment and gave him a beautiful and meaningful text about everyday expressions of the unconscious and that, thus elucidates the psychic expression of affects in terms of displacement and condensation.

Keywords: Drive; Intellect; Humour.

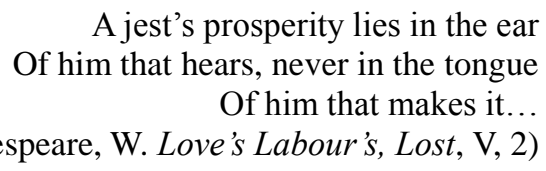

Muitas vezes Schopenhauer é tomado apenas por sua faceta mais folclórica: a do pessimista que considerava a vida uma inútil interrupção na ditosa paz do nada. Tratarse-ia de um filósofo de olhar severo e que achincalhava os seus inimigos; dentre estes, os mais atacados eram Schelling, Fichte e o seu preferido, o inimigo mais íntimo, mais amado, que como é bem conhecido, foi Hegel, considerado por ele um charlatão semespírito e confuso, e que por ser confuso, também escreveria de modo confuso. 
Para o autor de $O$ mundo como vontade e representação, os "três sofistas", como ele os caracterizou certa vez, amavam a verdade apenas até onde ela fosse conciliável com o interesse pessoal, ou, na medida em que correspondesse às regras de uma instituição temida, ou representasse os preconceitos e as preferências dos contemporâneos. Lançou sobre os três alguns violentos, porém bem-humorados ataques. Esses pensadores alemães seriam, de acordo com isso, artificialmente sérios, na verdade prestidigitadores, descarados, que teriam extrema confiança na imbecilidade das pessoas e no senso comum. Sua sentença sobre eles, em contraste com a sua própria posição, era a de que eles viveriam $d a$ filosofia e não para a filosofia, ou seja, seriam mercenários sem espírito.

A diatribe de Schopenhauer não deixa nunca de ser séria, embora ele ataque preferencialmente fazendo caricaturas de seus desafetos. De qualquer modo, por incrível que pareça isso demonstra que ele apresenta também uma face risonha, já que, para ele, o humor é uma das formas mais adequadas para a expressão das coisas mais sérias. Com o avanço dos estudos schopenhauerianos, a compreensão de sua complexidade e de sua importância como filósofo expõe, de fato, nuances insuspeitas de sua obra, que, sob muitos aspectos, anuncia e antecede a filosofia de Nietzsche e a psicanálise de Freud. Ele não seria, mediante uma análise mais aprofundada, um filósofo compreensível para os seus contemporâneos, por tratar de temas que se tornariam mais expressivos apenas na cultura do século $\mathrm{XX}$ e apenas em nossa época atual são estudados com o rigor que merecem.

Um desses temas presentes em sua obra e que merecem uma análise a partir da psicanálise é a sua teoria do riso - "das Lachen”-, sob a qual, como uma das suas expressões mais características, está o chiste, tema que entreteve por um breve momento o pensamento de Freud e lhe proporcionou um belo e elucidativo texto acerca das expressões cotidianas do inconsciente e que, dessa forma, elucida a expressão psíquica dos afetos em termos de deslocamento e condensação.

A análise do fenômeno do risível aparece especialmente em dois momentos: no décimo terceiro capítulo do Tomo I e no oitavo capítulo do Tomo II, intitulado Sobre a Teoria do Risível (Zur Theorie des Lächerlichen). A tradução acompanha a de Jair Barboza para "Wirkung des Lächerlichen" (efeito do risível) e "die richtige Erklärung des Lächerlichen" (explanação correta do risível).

Em Schopenhauer, o efeito humorístico nos é proporcionado pelo contraste entre representações intuitivas e abstratas, o que é fortemente enfatizado nos sete primeiros 
capítulos do Tomo II (Complementos da segunda edição de 1844) de $O$ mundo como vontade e representação.

Para o filósofo, a origem do riso é sempre a "insuspeita e paradoxal subsunção de um objeto sob um conceito que lhe é heterogêneo sob outros aspectos"1.

De acordo com isto, o fenômeno do riso significa "a súbita compreensão de uma incongruência (Inkongruenz) entre o referido conceito e a coisa pensada, e também entre o que é abstrato e o que é intuitivo. Quanto mais inesperada for esta incongruência na apreensão da pessoa que ri, tanto maior será a risada." ${ }^{2}$.

Assim, toda vez que a risada for provocada, será necessário que haja um conceito, que é o modo de conhecimento da razão, e algo particular - uma coisa ou um evento que poderia com certeza ser subsumido sob aquele conceito, mas que sob outro aspecto mais importante não se refere a ele e difere de tudo o mais que pode ser pensado sob ele.

Ou seja, no riso ocorre como uma reação frente ao desajustamento entre conceito e entendimento intuitivo. Para que o riso ocorra, é preciso uma aparência de correção entre conceito e intuição, que de um modo súbito se percebe ser uma subsunção paradoxal.

Embora a razão em geral esteja em conformidade com a representação intuitiva, é congruente com ela a ponto de em toda parte poder substituí-la, cito Schopenhauer, "nunca lhe corresponde inteiramente". ${ }^{3}$ É justamente ao percebermos a disjunção entre uma coisa e outra, entre conceito e representação intuitiva, que surge o riso.

O efeito do riso se origina da súbita compreensão do paradoxo. É indiferente se este efeito do inesperado se expressa por atos ou palavras.

No caso dos atos, a graça está no contraste com os conceitos com os quais aqueles são comparados. Schopenhauer nos dá a contragosto seus próprios exemplos, mas, no fundo, crê que cada um deveria imaginar os seus. Ele quer, segundo seu próprio testemunho, ajudar "aqueles leitores cuja inércia psíquica [Geistesträgheit] faz com que sempre prefiram permanecer num estado passivo". Ele escreve, com ironia: "Quero que fiquem confortáveis"4.

1 SCHOPENHAUER, A. WWVE, O Mundo como Vontade e Representação: Complementos, p. 99. Traduzido por Eduardo Ribeiro da Fonseca da edição publicada por Paul Deussen (Schopenhauers Sämtliche Werke, Piper Verlag, München 1911-1926, Bd. I-VI.), que é baseada na última revisão feita por Schopenhauer em vida.

2 Idem ibidem.

3 SCHOPENHAUER, A. WWV. O Mundo como Vontade e Representação, traduzido por Jair Barboza. p. 109.

4 SCHOPENHAUER, A. WWVE. O Mundo como Vontade e Representação: Complementos. Curitiba: Editora UFPR, 2014, p.156. 
Partindo para os exemplos, aqui eu imagino a cena da dança de Carlitos (Chaplin), no filme "Em busca do ouro", que explora a paisagem gelada do Alasca para provocar riso. Nessa cena Carlitos quer dançar com uma moça, mas a sua calça está frouxa. É nessa hora que ele confunde a corda que serve de coleira a um cachorro com uma corda comum. Ele prende a calça com a coleira. O cachorro resolve perseguir um gato e o leva junto. Penso também na célebre sequência da alucinação, na qual o companheiro esfomeado de Carlitos o confunde com uma enorme galinha e o persegue com uma faca, numa cena de antropofagia involuntária. Estaríamos presenciando uma tentativa de assassinato, mas damos risadas. Por quê? Poderíamos pensar, de acordo com Schopenhauer, que é devido ao absurdo contraste entre as intuições de um (alucinado de fome) e as de outro (o homem que de repente é atacado pelo companheiro de desventuras esfomeado).

No caso dos chistes, no entanto, há uma relação entre dois conceitos:

Se, como ocorre frequentemente com os chistes, em vez de um tal objeto real de intuição, trata-se de um conceito específico subordinado a outro mais genérico, o riso se produz porque a imaginação [Phantasie] se dá conta disso. Em outras palavras, ela coloca um representante no lugar da intuição, e, assim, consegue conceber o conflito entre o pensamento e o que é intuído 5 .

Nesse caso a que Schopenhauer se refere, penso mais no tipo de comédia feita por Wooddy Allen ${ }^{6}$ em seu filme Tudo o que você queria saber sobre sexo, mas tinha medo de perguntar, ${ }^{7}$ que parodia os capítulos de um famoso livro da época, escrito pelo médico David Reuben. Um dos papéis representados por Allen é o de um bobo da corte sem talento para a comédia que, na primeira história do filme, ${ }^{8}$ não consegue fazer rir, pois suas piadas não tem graça. Ela carrega um chocalho para marcar o momento do riso, mas ninguém quer saber de rir apesar disso, o que só aumenta o constrangimento. Para o público do filme, no entanto, a cena é engraçada. O que ocorre? É que justamente no contraste entre os conceitos de comediante e de sujeito sem graça ocorre a reação de riso. Rimos não da piada, nem do comediante, mas do conflito e do paradoxo existentes entre os dois conceitos simultaneamente personificados no bobo.

5 SCHOPENHAUER, A. O Mundo como Vontade e Representação: Complementos. Curitiba: Editora UFPR, 2014, p.156.

6 Woody Allen, nome artístico de Allan Stewart Königsberg, é um cineasta, roteirista, escritor, ator e músico norte-americano nascido em 1935.

7 “Everything You Always Wanted to Know About Sex (But Were Afraid to Ask)”, USA, 1972.

8 Referente ao capítulo "Do Aphrodisiacs Work?"

Sobre a seriedade do riso: as relações do chiste com o inconsciente em Freud

e a teoria do risivel de Schopenhauer 
Um exemplo dado por Schopenhauer, presente no Tomo II, é o do súdito que fez o seu rei rir quando este o viu em meio ao frio rigoroso do inverno vestindo roupas leves de verão. Ele disse ao rei: "Se Vossa Majestade vestisse o que estou vestindo, passaria calor". E quando the foi perguntado o que vestia, ele replicou: "Todo o meu guarda-roupa". Sob esse último conceito nós tanto pensamos no imenso guarda-roupa de um rei, quanto na única roupa de verão de um pobre diabo durante o rigoroso inverno. A visão de seu corpo tremendo de frio é muito incongruente com o conceito apresentado.

Sob o pretexto de explicar a diferença entre representações intuitivas, de primeira mão, e secundárias, de segunda mão, Schopenhauer nos fornece contribuições psicológicas que mais tarde interessaram também a Freud, independente do caminho que cada um seguiu para chegar às suas conclusões.

Neste sentido acima mencionado, um dos méritos da Teoria do Risível de Schopenhauer é mostrar a seriedade por trás do objeto do riso. A seriedade profunda é revestida com a embalagem do humor, de tal modo que torna possível integrar o objeto à consciência, coisa que do contrário não aconteceria. A forma como isto acontece é explicitada da seguinte maneira pelo filósofo:

\begin{abstract}
Em geral o riso é um estado prazeroso. A percepção da incongruência entre o pensamento e a intuição, isto é, a efetividade, deixa-nos alegres e nos entregamos com muito gosto ao abalo convulsivo [krampfhaten Erschütterung] que essa percepção provoca. O fundamento disso é a seguinte. Em cada um dos súbitos contrastes que aparecem entre o intuído e o concebido, o que é intuído está sempre indubitavelmente certo, porque a intuição não está sujeita a erro e nem necessita de confirmação vinda de fora, pois ela é a advogada de si mesma. Seu conflito com o pensamento resulta do fato de que este último, com seus conceitos abstratos, não pode abarcar a infinita variedade de matizes e as delicadas sutilezas do que é intuído. Esta vitória do conhecimento intuitivo sobre o pensamento nos alegra ${ }^{9}$.
\end{abstract}

Para Schopenhauer, isto ocorre porque a intuição intelectual (entendida como a representação primária da efetividade) é originária. Ela é a forma de conhecimento inseparável da natureza animal, que primariamente visa tudo o que pode ser objeto de satisfação imediata da vontade, entendida, neste contexto, como o querer e o modo de satisfação de desejos tal como são adequados a um caráter humano determinado.

A representação intuitiva é vista como o médium do presente, do prazer e da alegria. E, do ponto de vista de sua atividade, não depende de nenhum esforço. É

9 SCHOPENHAUER, A. O Mundo como Vontade e Representação: Complementos. Curitiba: Editora UFPR, 2014, p.164. 
espontânea. Mas, com o pensamento ocorre justamente o contrário, pois ele é o conhecimento em segunda potência, cujo exercício requer algum esforço, e, às vezes, um esforço até bem considerável. Aliás, a racionalidade é a forma de conhecimento na qual na qual os conceitos contrariam a satisfação (Befriedigung) de nossos desejos imediatos (unmittelbaren Wünsche), pois como intermediária entre passado, presente e futuro, e do que é sério, ela age como veículo para os nossos medos, nossos arrependimentos, e nossos cuidados (consideremos aqui o princípio de realidade enunciado por Freud e sua relação de contraste e complementaridade com o princípio de prazer). Por conseguinte, deve ser agradável para nós ver aquela estrita, incansável e também tão problemática governanta, a nossa "faculdade de razão" (Vernunft), a racionalidade, ser por vezes condenada por inadequação. É por isso que a expressão do riso e a alegria estão intimamente relacionadas. É como se tivéssemos um alívio por ver a racionalidade em condição ultrajante, após sermos tão oprimidos pelas suas exigências na experiência comum da vida.

Quando Schopenhauer fala em uma racionalidade que contraria nossos desejos, eu acredito que seja completamente inevitável evocarmos Freud e passarmos a recordar algumas de suas ideias afins. É claro que o psicanalista não está em busca de uma Teoria do risível de um modo geral e nem no que é simplesmente cômico. Ele se atém diretamente ao chiste, e, definindo o sentido específico da palavra no contexto freudiano, usa-se o termo na acepção de pilhéria, de um dito espirituoso e que geralmente não parece imediatamente ofensivo para quem ouve. Como ocorre em Schopenhauer, o principal objetivo de Freud é esclarecer o aspecto sério que se esconde ao fundo da piada, isto é, a relação com as disposições inconscientes do seu autor, inclusive a necessidade de contar e a observação dos efeitos em quem ouve o chiste. $\mathrm{O}$ aspecto relevante que também é considerado se refere a como o chiste serve de veículo para expressar coisas que de outro modo seriam alvo de censura psíquica e assim podem ser sublimadas e participar da vida consciente das pessoas.

Naturalmente, deste modo, o chiste era para Freud uma excelente maneira de expor às pessoas a natureza dos fenômenos inconscientes, pois permitia descrever o funcionamento do psiquismo mais amplo, cujos processos mais sutis (por exemplo, as intenções inacessíveis ao intelecto consciente) eram descritos mais por poetas e filósofos do que por pesquisadores empíricos. Esta ingrata missão resulta em magníficos textos do primeiro Freud, dentre os quais a Interpretação dos Sonhos, os Três ensaios sobre a sexualidade e este ao qual nos referimos nesta reflexão tão séria quanto bem-humorada, chamado por Freud de Os chistes e a sua relação com o 
inconsciente. Este texto não é o único local de sua obra que podemos buscar referências sobre o tema, mas é, sem dúvida, o seu trabalho mais completo a respeito, ainda que seja digno de nota que, ao contrário do que acontece com os outros trabalhos mencionados, não tenha recebido modificações posteriores, o que desperta a suspeita de que Freud tenha se desinteressado por ele e não lhe tenha atribuído grande importância no contexto de sua obra.

Mas, ainda assim, por que Freud se dedica a falar sobre o humor no contexto das piadas? No curso da discussão da relação entre os chistes e os sonhos, na parte teórica do texto, Freud menciona sua própria razão subjetiva para dedicar-se ao problema dos chistes. ${ }^{10}$ Tratava-se, em poucas palavras, do fato de que Wilhelm Fliess fizera um comentário de que os sonhos estavam por demais cheios de chistes, ao ler as provas de “A Interpretação de Sonhos" (1900) no outono de 1899. ${ }^{11}$ De acordo com Freud, "os processos de condensação, com ou sem formação de substitutivos, de representação pelo nonsense ou pelo oposto, de representação indireta", que desempenham uma parte na produção dos chistes, "mostram uma concordância muito abrangente com os processos de "elaboração onírica",. 12

Como Freud observa no texto sobre os chistes, o livro sobre $A$ Interpretação dos Sonhos havia deixado as pessoas mais desconcertadas do que esclarecidas a respeito dos fenômenos inconscientes, e, portanto, parecia serem necessárias novas explicações dos processos psíquicos, em especial as condensações e deslocamentos, que pareciam não ter sido bem compreendidos pelos leitores interessados na obra inaugural da "jovem ciência" da psicanálise.

O mecanismo psicológico dos chistes estaria então vinculado ao afeto, e, do mesmo modo em Schopenhauer, na medida em que a intuição serve ao querer. Esta conexão íntima de toda representação com a vontade permite os bailados da linguagem, a sua profusão de máscaras que, tais como o que ocorre no sonho, admitem também a aparente incongruência relacionada aos chistes e que, no fundo, permanecem precisos como a seta que acerta o centro do alvo. Para nós, psicanalistas, aparece realçada a importância econômica do humor, na medida em que a inteligência ilumina os

10 FREUD, S. El chiste y su relación con lo inconciente. In: Obras completas, v. 8 (1905). Tradução de José L. Etcheverry. Buenos Ayres: Amorrortu Editores, 1976, p. 153.

11 Segundo Strachey em seu famoso comentário ao texto de Freud, o episódio já fora narrado em uma nota de rodapé à $1^{\mathrm{a}}$ edição da própria A Interpretação de Sonhos (1900a); mas, há também a carta em que Freud respondia ao seu amigo Fliess. Foi escrita a 11 de setembro de 1899, de Berchtesgaten, onde foram dados os toques finais ao livro, e anuncia que Freud pretende inserir nele a explicação de um fato curioso: a presença nos sonhos de algo que se assemelharia aos chistes (Freud, 1950a, Carta 118).

12 FREUD, S. El chiste y su relación con lo inconciente. In: Obras completas, v. 8 (1905). Tradução de José L. Etchevcrry. Buenos Ayres: Amorrortu Editores, 1976, p. 153. 
contrastes entre as coisas e, do mesmo modo que o paradoxo e as oposições dialéticas são fontes de angústia, a falsa resolução proporcionada pelos chistes nos permite o alívio momentâneo das pressões geradas pela própria intelectualidade e pela apreensão intuitiva do mundo, permitindo um instante de relaxamento, um momento de recreio no pátio da escola da vida, que nos ensina através do sofrimento, amparada pela nossa intuição empírica dos objetos. É algo que, nas palavras do filósofo, trava por alguns instantes a roda de Íxion, permitindo um pequeno e momentâneo alívio para o desprazer associado à experiência do viver e nos elevando a uma posição mais leve e risonha, apesar de tudo o que nos inspira medo e quem sabe horror.

\section{Referências bibliográficas}

FREUD, S. Das Werk. Berlim: Heptagon Verlag, 2010. Edição digitalizada das obras de Sigmund Freud.

. Obras Completas. Madrid: Biblioteca Nueva, $1^{\text {a }}$ edição, 1996.

. Obras completas, v. 8 (1905). Tradução de José L. Etchevcrry. Buenos Ayres: Amorrortu Editores, 1976.

. Edição Standard Brasileira das Obras Completas de Sigmund Freud, 23 volumes. Rio de Janeiro: Imago, 1987.

SCHOPENHAUER, A. Sämtliche Werke. Textkritisch bearbeitet und herausgegeben von Wolfgang Frhr. von Löhneysen. Frankfurt: Suhrkamp, 1986. 5 Bd.

. Schopenhauers Sämtliche Werke. Hrsg. von dr. Paul Deussen. München: Piper Verlag, 1911-1926. Bd. 1-6.

Die Welt als Wille und Vorstellung, [O Mundo Como Vontade e como Representação] - 1819 (1 a. Ed.), 1844 (2a. ed.); 1859 (3a. ed). Tradução brasileira de Jair Barboza, São Paulo, Unesp, 2005.

Die Welt als Wille und Vorstellung, Ergänzungen [O Mundo Como Vontade e Representação: Complementos]. - 1844 (2 a. ed.); 1859 (3a. ed). Traduzido por Eduardo Ribeiro da Fonseca. Curitiba: Ed. UFPR, 2014. 